\title{
Entrepreneurship and Knowledge Integration are Part of a Liberal Education for the Knowledge Society
}

\author{
Frank Devitt
}

\section{Introduction}

\section{Liberal Arts and the Sciences; Knowledge Society}

Since the first half of the nineteenth century there has been a growing divergence within universities between the studies of the liberal arts and those of the natural sciences, technology and engineering. This has arisen because of the rapid developments in these latter areas and their perceived need for specialisation and presumed lesser importance of liberal arts subjects. In this context the term liberal is generally understood to mean freedom to range over a broad range of knowledge, without being constrained to serve any particular application area, or even purpose.

Practically all $21^{\text {st }}$ century first-world countries aspire to be Knowledge Societies and many have active programmes under way to support and foster this progress up the value chain. ${ }^{6,7}$ It is hard to find objectors to this trend; after all, what is the alternative, a no-knowledge society? Knowledge, once gained, can't be easily destroyed and is generally recognised as a good thing; however, there is still debate about the relative values of different types of knowledge and, indeed, the nature of knowledge itself.

In Ireland, in common with most of Europe, more than 50\% of young adults in the age range 18 to 22 attend third level colleges and about $55 \%$ of these are universities. This is a huge change from a century, or even a half century, ago, when less than $10 \%$ of these rates applied. Now, with rapid knowledge advancement, there is also a requirement for life-long learning in order for one's competence or expertise to stay current.

\section{Liberalism Equates to Utility}

In this paper, the substantial changes that have occurred in the above areas since 100 years ago are considered and conclusions drawn as to how universities should respond. It is argued that a liberal education remains an important style of education, particularly at undergraduate level, and is the proper domain of a university, but with a necessary, and overdue, re-interpretation. A modern liberal education must cover the range of subjects that are necessary for survival in and contribution to modem society. Entrepreneurship and integration of disparate knowledge areas are essential additions to the classical subjects. With this understanding, true liberalism equates to maximum utility. This is true, notwithstanding that many university academics would not be comfortable with this juxtaposition. Traditionalists are sometimes alarmed at the changes to university education in response to a changing society. The discussions in this paper show that there is much to be gained rather than feared from university adaptation to the knowledge society.

\section{Knowledge is Ubiquitous}

Knowledge has been democratised, and knowledge advancement is ubiquitous. Universities no longer have special claim to unique expertise in any one area. The university can establish a unique position for itself among the various knowledge 
society members, including non-university institutions, through focusing on knowledge integration as its key role relative to knowledge advancement.

\section{Practice Informed Teaching}

The primary role of a university is teaching, even more so in a knowledge society. University-based research is not enough to support expertise in teachers, as implied by Research Informed Teaching. Experiencing the whole, global practice of knowledge application, advancement and integration is better represented by replacing the foregoing with a more apposite guiding rubric, Practice Informed Teaching.

\section{Paper Structure}

The paper is structured as follows.

Section 1 provides background by reviewing the origins and exploring the concept of liberal education.

Section 2 explores the understanding of howledge and its utility, particularly as relevant to university activities.

Section 3 focuses particularly on research, within and outside universities, and the evolution of multiple specialisations, which requires a new role of knowledge integration. It addresses the role of research, or knowledge advancement, in supporting university teaching.

Section 4 explores the meaning of entrepreneurship and shows how this is relevant, even essential, for fully participative and contributory living in a knowledge society.

Section 5 brings together the understanding of the knowledge society, multiple knowledges integration and entrepreneurship to re-define liberal education for the $21^{\text {st }}$ century.

Main points and analysis outcomes of the paper are presented in the conclusions of section 6.

\section{Background}

\section{Liberal Education}

Practically all modern universities aspire to provide a liberal education, at least to some of its students; other studies, e.g. of the natural sciences or the professions, are often considered less appropriate for application of the term or concept of liberal. Where this arises, it stems from a misunderstanding of the term, which has resulted in a stagnation of its presumed content since the $19^{\text {th }}$ century. The meaning of the term liberal education needs to be revisited and its scope updated.

The still dominant model for a contemporary university is founded upon the views of $19^{\text {th }}$ century thinkers such as Wilhelm von Humboldt, founder of Berlin's University in 1810, and John Henry Cardinal Newman, founder of the Catholic University of Ireland, Dublin in 1852. From these, the primacy of concepts such as allgemeine Bildung (well-rounded education), non-utliry, liberal education, knowledge its own end were established and continue to guide, at least in principle, most universities. Whereas Newman saw teaching as the primary role of a university, Humboldt was more strongly of the view that research and teaching went hand in hand. 


\subsection{Purpose of a University}

\section{Newman et al.-Teaching and Research}

For Newman, the primary role of a university was teaching rather than research.'

[A university] is a place of teaching universal knowledge. This implies that its object is ... the diffusion and extension of knowledge rather than the advancement [of knowledge]. If its object were scientific and philosophical discovery, I do not see why a University should have students ...

In this respect Newman was in disagreement with Humboldt who, earlier in the nineteenth century, had maintained that teaching and research were the 'dual roles of the university'. Pelikan agrees with Humboldt and refers to other comments of Newman, viz.

the enlargement [or enlightenment, for which education strives] consists, not merely in the passive reception into the mind of a number of ideas hitherto unknown to it, but in the mind's energetic and simultaneous action upon and towards and among those new ideas, which are rushing in upon it. ${ }^{2}$

Pelikan argues strongly that ...

... such an action of the student's mind, and even more of the teacher's mind, would appear to demand that the passive reception of communicated knowledge be replaced, or at any rate accompanied, by an active participation in the very processes by which knowledge is advanced......

For such a student the learning process does not mean, or does not mean only, learning the What of existing knowledge but learning the How of as yet unknown knowledge. ${ }^{9}$

\section{Preparation for Life}

Newman considered a university education to be a preparation for life and for proper living and, to some extent, for the gracious and noble living of a Gentleman. The product of a university education would be a gentleman with ...

a clear conscious view of his own opinions and judgments, a truth in developing them, an eloquence in expressing them, and a force in urging them.

A university education ...

teaches him to see things as they are, to go right to the point, to disentangle a skein of thought, to detect what is sophistical, and to discard what is irrelevant. It prepares him to fill any post with credit, and to master any subject with facility. It shows him how to accommodate himself to others, how to throw himself into their state of mind, how to bring before them his own, how to influence them, how to come to an understanding with them, how to bear with them. He is at home in any society, he has common ground with every class 2 
Humboldt seemed to have a more democratic ideal for his university education system. In reforming the Prussian education system in the early nineteenth century Humboldt sought to create citizens capable of thinking for themselves. 'The most ordinary day labourer' must have the same Fundament (basic education) as 'the most highly educated person'. He also said 'every part of the [three-tier education] system should be interlocked with every other part'.

Humboldt was guided by the concept of allgemeine Bildung that was a lifelong process and distinct from vocational or professional training. Allgemeine Bildung was meant to inform teaching at all three levels of the Prussian school system, viz. elementary, secondary, and university. Through allgemeine Bildung, each person might seek to realise the human potential that he possessed as a unique individual.

\subsection{Liberal University Education Benefits Society and the Individual}

\section{For Whose Benefit?}

For whose benefit does a university exist? Most contributors agree that a university, somehow, should contribute to society. Newman saw this clearly as being effected through the training of the individual.

That training of the intellect, which is best for the individual himself, best enables him to discharge his duties to society....

If then a practical end must be assigned to a University course, I say it is that of training good members of society. Its art is the art of the social life and its end is fitness for the world. ${ }^{2}$

It is an unsurprising proposition that a university should function primarily for the benefit of its students individually and for society in general. This remains a basic premise for most contemporary universities.

\section{How is Benefit Realised?}

The benefit transfer is achieved in many direct and indirect ways. The liberal, nonutility educational model favours the indirect method, whereas the utilitarian model seeks to provide more direct benefits. In liberal education, it is supposed that universal knowledge is absorbed into the student's mind and in so doing the mind is formed and prepared for mature absorption and analysis of further knowledge, in whatever field the student may be later engaged.

By contrast, in the utilitarian practice of higher education, students are taught more directly the knowledge of a particular profession or set of knowledge required by a particular sector or activity of society. They are thus more readily and immediately of benefit (productive) in the professional activity area studied.

\section{Liberal Education Must be Broad}

But liberal and utility educations need not be mutually exclusive. If a liberal education is concerned with preparation for life and for being able to evaluate wisely, appreciate, adjudicate on and contribute to the various circumstances of life's existence, then this process of preparation is the better performed as more of relevant 
knowledge is considered. In living a modern life, particularly in a knowledgedynamic society, there is a wide range of knowledge areas that are relevant. It seems unnecessary to agonise for too long in trying to decide whether one is better than the other. A truly liberal education demands a broad treatment of all major knowledge areas.

It may be considered that balance across knowledge areas or types would be satisfactorily applied on a national or regional basis. Such global approaches neglect the individual student who should be the focus of the education. It is within each student that the integration, amplification and application of the broad liberal education must take place. Therefore, it is the individual student who must be educated in a collegial and multi-disciplinary atmosphere.

To the extent that the desired universality of a truly liberal education is restricted to any one discipline or narrower set of disciplines, so the proclaimed value of such a liberal education is diminished. It is, therefore, surprising and regrettable when one encounters, as occasionally happens, for example, a Humanities education masquerading as a liberal education, with variously the university or the student as the masquerader; this travesty is mitigated somewhat where the physical sciences are included, as should have been justified throughout all of the $20^{\text {th }}$ century. But, the dynamic and complexity of the knowledge society requires still further expansion of the scope of education necessary for qualification as liberal in the $21^{\text {st }}$ century. This is considered further below.

Newman, once again, addressed these points most eloquently: ${ }^{2}$

There is no science but tells a different tale, when viewed as a portion of a whole, from what it is likely to suggest when taken by itself, without the safeguard, as I may call it, of others.

And later:

It is a great point then to enlarge the range of studies which a University professes, even for the sake of the students; and, though they cannot pursue every subject which is open to them, they will be the gainers by living among those and under those who represent the whole circle. This I conceive to be the advantage of a seat of universal learning, considered as a place of education. An assemblage of learned men, zealous for their own sciences, and rivals of each other, are brought, by familiar intercourse and for the sake of intellectual peace, to adjust together the claims and relations of their respective subjects of investigation. They learn to respect, to consult, to aid each other. Thus is created a pure and clear atmosphere of thought, which the student also breathes, though in his own case he only pursues a few sciences out of the multitude. He profits by an intellectual tradition, which is independent of particular teachers, which guides him in his choice of subjects, and duly interprets for him those which he chooses. He apprehends the great outlines of knowledge, the principles on which it rests, the scale of its parts, its lights and its shades, its great points and its little, as he otherwise cannot apprehend them. Hence it is that his education is called 'Liberal'. A habit of mind is formed which lasts through life, of which the attributes are, freedom, 
equitableness, calmness, moderation, and wisdom; or what ... I have ventured to call a philosophical habit. This then I would assign as the special fruit of the education furnished at a University, as contrasted with other places of teaching or modes of teaching. This is the main purpose of a University in its treatment of its students.

This is an agreeable, holistic, inclusive idea of a liberal education and the manner in which it takes effect. By way of emphasis, there can be little so antithetical to the concept of liberal education than that its graduates should proclaim themselves (proudly, as some do) ignorant of any substantial body of knowledge, especially, but not solely, classical knowledge. And yet, it is not uncommon to hear Humanities graduates declare proudly that '[ $I$ have] always been hopeless at mathematics' or similar cringe-worthy remark. And vice-versa; one regularly experiences mathematicians and natural sciences graduates casually disavow knowledge of the Humanities, or implicitly do so by showing an alarming incapability or lack of concern in respect of written or verbal communication. Thus it is that a broad education within a single institution provides the better education solution for the university, the student and hence for society.

\section{Knowledge}

\subsection{Types of Knowledge}

Teaching universal knowledge is a tall order, all the more so as the stores of knowledge increase exponentially with time. For such a central concept in the debate about universities, it is reasonable to ask the question 'what is knowledge?', One way to identify the encompassment of knowledge is to consider the hierarchy (variously referred to as the Wisdom or Knowledge or Information Hierarchy) represented by the paradigm Data-Information-Knowledge-Wisdom. This has found prominent use in the Information Technology and Knowledge Management studies of the last two decades. Here, broadly, Data equates to raw facts, or measurement results; Information equates to classified or categorically arranged data; Knowledge exists when reasoning or rules of integration and inference are applied to information with a consequent ability to understand or solve problems. Wisdom is often understood as a global application of such rules of integration and inference, where they are applied across all areas of knowledge rather than local to one knowledge area. This conception of wisdom seems close to the idea of universal knowledge, as used by Newman.

Newman's definition of knowledge was:

When I speak of Knowledge, I mean something intellectual, something which grasps what it perceives through the senses; something which takes a view of things; which sees more than the senses convey; which reasons upon what it sees, and while it sees; which invests it with an idea. ${ }^{2}$

And, what is not knowledge:

... it seems to me improper to call that passive sensation, or perception of things, which brutes seem to possess, by the name of Knowledge. ${ }^{2}$ 
Knowledge for Direct and Indirect Application

Knowledge may be encountered as different types and in different ways. It may have direct application (utility) and it may have no or indirect application (liberal). Actually, Newman's justification that acquiring new knowledge results in a 'training of the intellect' of the individual that ultimately leads to a benefit for society has the implication that all knowledge can have some application.

Classical knowledge was concerned more with the person and with the person's development and relationship with the Universe and the Creator; it had very little to do with the individual's everyday occupation. The new knowledge of the knowledge society is more concerned with the application areas in which it may be applied. Peter Drucker has said: 'In the knowledge society, knowledge basically exists only in application', ${ }^{8}$ and he proposes use of the term knowledges to indicate the multiplicity of disparate sets of knowledge that have grown as part of that society.

\subsection{Knowledge its Own End}

\section{A Realistic Mission for an Institution?}

This key principle arising out of the Idea of a University discourses is revered in many university circles, a reverence that has been sustained through the beautiful simplicity and nobility of its image. It brings to mind an Elysian existence where scholars are motivated by the noble quest, untainted by baser temporal concerns. There is no doubt that knowledge and its quest are very satisfying to all individuals, as well as being a gateway to opportunity and power. But, inevitably, knowledge its own end may be truly realised only in a context of extreme elitism; it is amenable only to the elite few who are, or whose families or supporters are, of independent material means and who do not bear a normal burden of self-sustenance or who do not carry a responsibility to contribute to greater society. Outside of this very restricted few, all others must keep their own material sustenance in mind, because no other person or entity will look after it in their stead. Certainly, the state must have, most philanthropic sponsors will have and even Newman on occasion did have an ultimate goal other than solely the satisfaction or fulfilment of a scholar or student, and that ultimate goal is, at least, the benefit of general society.

Knowledge its own end is not a reasonable or practical strategy for a modern university, although it remains an innate motivating force for the individual, as evidenced by the recreational popularity of crosswords and quizzes. For the university there must be a purpose, a performance or an output that benefits somebody or some entity; that is the only reality.

\section{He Who Pays the Piper Calls the Tune}

Whom or what does a university benefit; how and over what time-scale should the benefit accrue? This is the perspective from which debate concerning the role of a university can be usefully engaged. In the first instance it is obviously a matter for the benefactor; he who pays the piper calls the tune. However, it is of course possible that the state or other benefactor might simply require a university mission to benefit society and leave the strategy for achieving this up to the institution. In turn, society's interests will be best served by a balance of benefits, spread over time and over knowledge type. 
It is open to the university to advise the state, or other benefactor, as to the best methods for evaluating its societal benefit contribution, although such advice may or may not be adopted. In turn, the state might incentivise the university to perform this contribution optimally and according to its wider requirements. As with most strategic management plans, the incentivisation will be better achieved by targeting university outputs rather than internal process parameters. The state should be more interested in the outputs such as graduate numbers and disciplines, quality of graduate intellectual development, research outputs and other benefits to society. Allowing individual universities to decide how to achieve the target outputs by their own separate means and internal processes will ensure better motivation, and healthy diversity.

\section{Research Publications}

In the context of knowledge its own end, it is worth considering the practice of university research publishing today. Most university academic staff members carry out research and publish the results of that research in journals. Why? In some cases it will be for philanthropic reasons, for the benefit of society; professionally, it is recommended practice as a means of peer review and verification or quality control of results; in many cases it is a simple necessity for career progression-publish or perish-and this may be sufficient justification.

\section{Motive is Not Important}

The relevance of the foregoing here is as follows. Newman and his followers address any element of knowledge in two ways, exemplified by the following ldea extract. ${ }^{2}$

I know well [knowledge] may resolve itself into an art, and terminate in a mechanical process, and in tangible fruit; but it also may fall back upon that Reason which informs it, and resolve itself into Philosophy. In one case it is called Useful Knowledge, in the other Liberal. The same person may cultivate it in both ways at once ... there are two ways of using Knowledge, and in matter of fact those who use it in one way are not likely to use it in the other, or at least in a very limited measure. You see, then, here are two methods of Education; the end of the one is to be philosophical, of the other to be mechanical; the one rises towards general ideas, the other is exhausted upon what is particular and external.

This argument suggests that knowledge with application is of limited intellectual developmental value and, perhaps, ceases to be knowledge as understood by Newman; the same knowledge is estimated to be, somehow, nobler by virtue of having no application. This is too fine a distinction to have relevance for the reality of university existence, strategy planning or administration in the $21^{\text {st }}$ century. The various academics who publish research results for philanthropic reasons on the one hand or for the more selfish end of career progression on the other hand are equally valuable, and effectively indistinguishable, members of the university community. As such, it is sufficient for the university administration to be content that each is somehow motivated to perform and produce output. 


\section{Knowledge Advancement and Knowledge Integration}

It is a sine qua non, but worth re-emphasising, of a discussion such as this to acknowledge that most university research is of a high quality, relevance and benefit to society. This paper addresses in particular aspects meriting augmentation.

\section{University Research Not Highty Regarded by All}

Research is a process of inquiry, of advancement of knowledge, as it was termed by Newman. University research partly has fallen into disrepute among some sectors outside of the university system, and some within it, due to the extremely indirect nature of its practice, for which a justification is usually offered under the rubric knowledge its own end.

Cynical commentators on university research maintain that at least some of it represents a process whereby more and more papers are written for the benefit of fewer and fewer readers and with less and less purpose. This means that a research specialism may be so entrenched and isolated of meaning or application for the world at large, even for the general academic world, that only rare, other peers in that specialism area are capable or interested to understand the outcomes. As Pelikan, who is fully in favour of research as an integral part of a university, acknowledges:

No defence of the principle [Knowledge its own end] will stand unless it begins with the acknowledgement that at least some of what passes for research ... is trivial, largely self-referential and devoted to belabouring the obvious. ${ }^{9}$

Such research is hardly conducive to benefiting society.

\section{Why Do University Research?}

The principal justification for universities to have research activity is maintenance or improvement of teaching quality through ensuring a teacher is up-to-date in the subject area of the teaching. Research Informed Teaching is considered optimal. As Newman said, albeit in part contradiction of his earlier ideas:

...in the university the teachers who extend the knowledge to students should also be the investigators who advance the knowledge. ${ }^{3}$

The German Humanities scholar Adolf von Harnack, early in the $20^{\text {th }}$ century, also proposed that it served to introduce students to the process of inquiry itself:

[In some countries] the chief emphasis lies on introducing students to the results of scholarship. But at our universities we want to introduce them to scholarship itself, and to teach them how one arrives at the reality of things and how one can advance the progress of scholarship."

Both of these justifications remain valid, and perhaps more so, in the knowledge society. Available knowledge advances ever more rapidly and the teachers' knowledge intake cannot stay static if they are to teach properly. Equally, students who will progress to employment in a knowledge-advancing environment must have an understanding of the principles involved. Nevertheless, it is a valid criticism to say that too much university research is of little relevance to most of the world, not least 
the students, as is supported by Pelikan above. It is questionable whether undergraduate or even much postgraduate teaching is informed to any extent by the type of research that is esoteric and disconnected from obvious extemal relevance.

\section{Research Must Have Relevance to Something}

Because universities and university teachers should be engaged in research, this does not mean that this research should not be useful or that a university is the only or primary place of research in our society. In the knowledge society such is not the case.

Some justification for isolation of university research and academic researchers and teachers appears to be based on protection of academia from corruption of and in the marketplace. Thus, Hogan says that

... academic freedom is an enduring necessity if a society is to be truly democratic rather than authoritarian; if truth seeking is to be capable of speaking to established power; if the best fruits of learning are to be openly voiced and criticised rather than silenced, or made captive to sectional interests. ${ }^{17}$

This is a strongly conservative viewpoint and even hints of paranoia. The sectional interests referenced are those of the market-place and of the economy, as opposed to broader society, as if participants in these areas should be denied the benefits of citizenship, such as access to university resources, for fear of university corruption. In so far as corporations are expected to be good citizens, and they are, then they should equally be entitled to the benefits of citizenship.

\section{Freedom of Scope v. Obligation to Integrity}

There are two freedoms being confused here. Certainly, academics, journalists and others should be free to tell the truth in whatever subject area they are addressing. Truth is more than a freedom for most professionals; it is an obligation. But, it is unreasonable to infer from this that academics should have total freedom in deciding the scope of their studies, possibly to an extent that is of no relevance to anyone else. If that were the case, how could society or any sponsor trust academics not to squander such a freedom? The brutal crux here is one of trust and human nature's tendency to submit to pressures (and commercial pressures are not the only ones) on the one hand, versus a tendency, without pressures, to dilettantism, laziness or selfindulgence on the other hand. Hogan appears not to trust university academics with the former, but is willing to do so with the latter. He appears to do so in the knowledge of the dangers, but then disregards any consequences of these dangers, when he says: 'Such freedom ... in one sense it is [a privilege], and of course it can be abused, sometimes disastrously so: ${ }^{17}$

\section{Diversity of Funding is the Key to Independence and Integrity}

A portion of general society, however and unfortunately for universities, makes the alternative choice to Hogan's, choosing not to trust academics with too much freedom, while being perhaps too unquestioning of the adequacy of safeguards in place in respect of academic dealings with state, commercial and other sponsors. Both sides are partly right and there is no merit in emphasising one side excessively while ignoring the other side. There is a fine balancing of freedom supports and freedom 
constraints that is necessary in order to optimise the extent to which academic research benefits society. Practically, this balancing is best achieved through multiplicity of sponsors. Pelikan says:

Yet private financial support for the university has historically been an important bastion of freedom against government intrusion.

...such interference [by business donors in the internal academic affairs of the university] has come to be the exception rather than the rule. ${ }^{9}$

\section{Knowledge Advancement has been Democratised}

In the knowledge society, knowledge is advanced in many diverse subject areas, in many ways, in many locations by many players. (Nearly) everybody is at it! It is a mistake for universities to believe that its members are in a position of high priesthood in this respect. Knowledge, its amenability to access and its advancement have been democratised through technology and widespread education. The contributors to knowledge advancement are individuals, groups, commercial corporations and many other types of institution, including, but not limited to, universities and research institutes.

There is no doubt that the criteria designated for evaluating academic research, in universities and in research institutes, may be equally validly satisfied also in other domains, though often this may be not explicitly emphasised or of interest to those involved. Take as an example a commercial corporation, small or large, involved in a technology business. Many such firms are at the forefront of expertise in their subject area and sell their expertise as much as any derivative products, although the former is often embodied in the latter. Of course, also, its priority and motivation properly is commercial success rather than explicit satisfaction of academic criteria. When such a business establishes new knowledge, or collates or integrates multiple knowledge advances, it will incorporate this new knowledge in a new product. In many ways such a real product acts as a model for testing and verification of the new knowledge; an academic researcher would create and evaluate an artificial such model as routine procedure. It is impossible and meaningless to say either knowledge is better than the other.

\section{What about Peer Review?}

There is more than one model for peer review and there can be few more rigorous peer reviews than those of the firm's customers, whose expertise is sometimes equal to that of the supplier and will be very firmly applied in assessment of the proposition for which they are expected to outlay perhaps millions of Euros. This peer review process is continuous and often done with specific negative intent, by competitors.

\section{The Wisdom of Old Age ... for the Young}

With such volume and variety of knowledge advancement there is a clear need for knowledge integration, deeper understanding, evaluation and archiving. This is equally in service of general society's knowledge advancement as much as pushing one or more of knowledge's leading edges. Traditional university research likes to be at the cutting edge and such edges are usually sharp, narrow and necessarily cover only a small section of knowledge at a time. Knowledge integration, of which professional practice is an example, deepens and broadens understanding by seeking out and observing nuances and interrelationships from new perspectives and in new 
circumstances, as these continuously arise due to changing environments and combined projects with other disciplines. Whereas cutting edge research concentrates on tangible, explicit new knowledge, practice and knowledge integration cultivate the tacit understanding of relationships, constraints and exceptions to a knowledge base. Knowledge integration is about establishing, expanding and tracking the paradigm of validity for existing and new knowledge. It is akin to the wisdom of age, normally achieved through years of practice. As Otiver Wendell Holmes said: 'Young men know the rules, but old men know the exceptions'. Integrative learning spceds up this aging process (in a manner of speaking).

\section{Practice Informed Teaching}

In view of the foregoing, one might view the ideal university teacher more appositely as a knowledge practitioner rather than researcher so that Practice Informed Teaching defines the best motif by which to impart a modern liberal education. The practice may be experienced by traditional university research, corporate-centred research or application, integration of multiple knowledge sets in a university or in the extra-university world, as happens more naturally and more often. Ideally and optimally, all such experiences would be available to the teacher.

\section{Knowledge Advancement-A Mining Metaphor}

Knowledge advancement in the knowledge society may be visualised with a mining metaphor, where a varied geological earth structure represents the variety, breadth and depth of knowledge to be mined. Various researchers choose different areas to conduct their research.

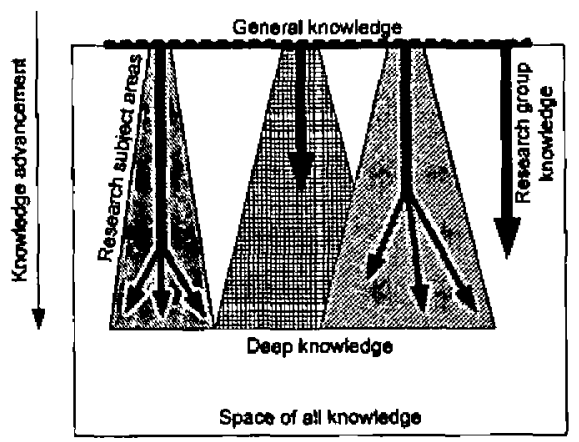

A research group may dig in one location and find new nuggets in its own area. Likewise, other groups may dig and find their own nuggets. More knowledge gaps exist as specialisation advances. 

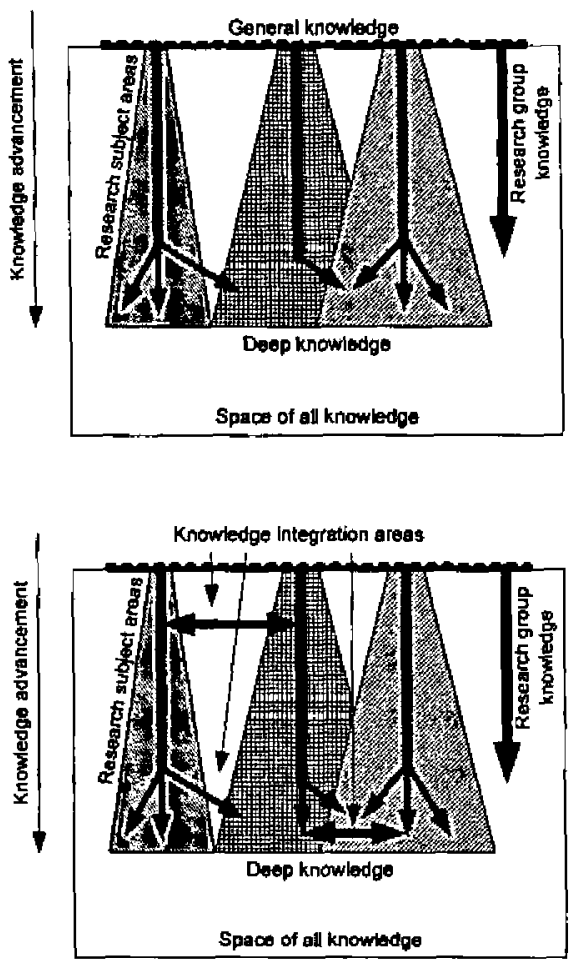

Some knowledge areas overlap, leading to more rapid advancement in one or more areas through multidisciplinary cooperation.

Isolated shafts of knowledge mining leave large areas of un-mined knowledge between and outside the already-explored areas, as well as opportunity for re-interpretation of common knowledge areas.

\section{University Research Should Not be Isolated}

University academic research is part of a distribution of knowledge advancement throughout the various institutions and sectors of the knowledge society. There is no very useful role for isolated research, for the more isolated it is then it is all the more likely to be irrelevant and useless. Fervent disciples of Newman's knowledge its own end maxim might regard this as complementary, but more will not and Newrnan provides support for these also, as quoted above.

\section{University Not the Unique Leader-but a Leader Among Peers}

The role of a university has changed hugely through the $19^{\text {th }}$ and $20^{\text {th }}$ centuries, from being one of a few similar institutional centres of scholarship to being one among many knowledge players. This compares closely with the changed philosophy of Organisation Management, as it has evolved through the latter half of the same period. From assuming a traditional captain's role of pushing, driving and commanding, the manager's role has changed to a leader's role of motivating, organising, facilitating. Similarly, the university now can be, in one sense only, one among many different types of knowledge advancers. The university researcher must aspire to be a leading influence, not the leader. The university must define its new role as a leader and facilitator among peers of diverse types and in various settings. 
General Bill Creech ${ }^{5}$ chronicles the way even a strongly hierarchical organisation such as the US Air Force Tactical Air Command, when organised and led as a knowledge organisation, loses its hierarchical relationships and assumes a collegia] behaviour as part of overall performance improvement. So is it with the knowledge society.

\section{Entrepreneurship}

\section{The Meaning of Entrepreneurship}

There are many reviews in the literature of the meaning of the term entrepreneurship, as it has developed, and continues to develop, since its introduction to modem usage by $18^{\text {th }}$ century economists Richard Cantillon and Jean Baptiste Say. The word was originally used to mean a self-employed person with a tolerance for the risk inherent in providing for one's own economic well being. This was later expanded to include the possession of managerial skills. Say used the word to describe 'the venturesome individuals who stimulated economic progress by finding new and better ways of doing things ... The entrepreneur shifts economic resources out of an area of lower and into an area of higher productivity and yield'. ${ }^{21}$

Economist Joseph Schumpeter ${ }^{13}$ further refined the concept in the early $20^{\text {th }}$ century when he described entrepreneurship as being the primary engine of economic growth. Its essential tool, innovation, allows economic systems to avoid repetition and achieve progress by serving new markets or creating new ways of doing things. In his words, '... the function of entrepreneurs is to reform or revolutionise the pattern of production'. They can do this in many ways, 'by exploiting an invention or, more generally, an untried technological possibility for producing a new commodity or producing an old one in a new way, by opening up a new source of supply of materials or a new outlet for products, by reorganising an industry and so on'.21

\section{Entrepreneurs Create Value}

When asked to provide the names of prominent entrepreneurs, most groups will list well-known, successful business people. This is the most popular and vernacular understanding. But, there is a growing recognition that entrepreneurship is more than an aptitude for or attitude to business; it is an attitude to life and of living and has application in many, perhaps all, aspects of life.

There has been a lot of study of the essential traits of an entrepreneur and of the requirements of entrepreneurship education, in particular through the last 30 years. This has given rise, more recently, to the recognition that these traits and characteristic modes of behaviour are not confined to the economic or business sphere. In fact, entrepreneurial behaviour, as identified, has been practised in various circumstances and contexts for centuries, though that name has not always been applied to such behaviour. In particular, the term Social Entrepreneurship has become common since the end of the $20^{\text {th }}$ century. As Stanford professor Gregory Dees says, '[Social entrepreneurship] combines the passion of a social mission with an image of business-like discipline, innovation and determination... Social entrepreneurs are needed to develop new models [for social sector institutions] for a new century'. 'Entrepreneurs create value', he says, and adds, 'Profit is not the gauge of value creation ... social impact is the gauge'. 18 
Peter Drucker does not require entrepreneurs always to cause change but focuses on the exploitation of opportunities that change creates. Thus, he says '... this defines entrepreneur and entrepreneurship-the entrepreneur always searches for change, responds to it and exploits it as an opportunity'. ${ }^{19}$ The opportunity in question is generally accepted as being an opportunity to create value. Dees says, 'entrepreneurs have a mindset that sees the possibilities rather than the problems associated with change. ... For Drucker, starting a business is neither necessary nor sufficient for entrepreneurship'. 18

\section{Entrepreneurial Characteristics}

Taking the above developments together with much other study and commentary there is a set of characteristics that is broadly accepted as the essence of an entrepreneurial mind-set. These mind-set or behaviour characteristics indicate that an entrepreneur is:

- Comfortable with change and innovation, whether responding to or causing the change.

- Comfortable with risk. This is sometimes misunderstood to mean that an entrepreneur always seeks out risk, and the more the better. Not so; the comfort is one of understanding the quantum of risk and parameters of a risk situation and having the ability to evaluate and balance the risk with the anticipated reward.

- Able and always ready to seek out and identify opportunity to add value.

- Able and motivated to mobilise resources beyond those immedjately available in order to achieve the value realisation.

- Capable of forming and maintaining a clear vision beyond the immediately obvious.

- Having a positive focus of mind or passion for success that refuses to be subdued by problems or occasional failure.

Adapting a recent definition: Entrepreneurship is the exercise of a set of attributes or behaviours towards identification of opportunities to add value and the mobilisation of resources necessary, with due regard to risk involved, to realise that added value. ${ }^{12}$

For clarity, Dees adds: 'Entrepreneurs mobilise the resources of others to achieve their entrepreneurial objectives. Administrators allow their existing resources and their job descriptions to constrain their visions and actions". ${ }^{18}$

Note, there is nothing in the above to mandate a business context although certainly this is also included.

\section{What Does an Entrepreneur Do?}

The entrepreneur seeks to add value; this value could be added to an individual, to an organisation, to society. The value may be realised in monetary forn or any alternative such as educational value, quality of life, environmental value, aesthetic value etc.

The entrepreneur mobilises resources as required; this implies knowledge or judgment of the scope and particular resources to be mobilised as well as a management ability to coordinate the realisation of the added value. 
The entrepreneur assumes risk; this implies strength of vision and an ability to evaluate and assess risk as well as the value being sought. An entrepreneur is not a daredevil, but a cool and competent, perhaps intuitive, assessor of risk to reward ratio.

The entrepreneur is comfortable with change and sees it as a natural order and a paradigm emphasised by opportunity and innovation rather than threat.

Above all, perhaps, the entrepreneur has a positive mind-set that focuses on the endvision and positively influences others to greater performance.

\section{Entrepreneurial Characteristics are Assets for Life}

It is uncertain to what extent entrepreneurship is an inherent trait for an individual or is amenable to education and development and it is beyond the present scope to deal with this in detail. It is certain, however, that the entrepreneurship characteristics above are found to varying extents in most individuals; it is also clear that many universities and other colleges world-wide believe they are amenable to further development as evidenced by the rapid growth in numbers of entrepreneurship faculties and courses. Unfortunately, these are mostly found associated with business schools only. Like other intrinsic individual abilities such as musicianship or art, intrinsic ability towards entrepreneurship will be enhanced in most individuals through education, study and learning.

The entrepreneurship characteristics are assets for life and for contributory living, particularly life in a knowledge society where change is a constant in most contexts. Entrepreneurship provides a positive framework for addressing life's circumstances in a positive, contributory way.

It is not implied that entrepreneurship is the unique panacea for all of life's difficulties. In a corporate setting, Adizes ${ }^{20}$ has described the way entrepreneurial traits are necessary for optimal governance but certainly are not sufficient and they must be blended with other characteristic types with emphasis on administration, leadership and performance.

\section{Knowledge Society; Entrepreneurship and Multiple Knowledge Integration; Liberal Education Revisited}

The knowledge society has progressed beyond the agriculture society, the mechanical society, the industrial society and through the information society. Whereas the information society has been technology led, the maturation to a knowledge society will be achieved through education, because it is education that provides the reasoning and connected understanding that transforms information into knowledge. In a sense, education is the necessary tool for processing information wisely into knowledge.

\section{Liberal Education to be Revisited}

The aspiration for a classical, well-rounded, liberal education is not being widely or popularly realised. There is much separation, misinformation and misunderstanding between distinct areas of knowledge, as referenced earlier. As the whole stock of knowledge grows, so does the tendency towards specialisation. The response of many 
educational institutions, teachers and learners, while assuming a finite individual learning capacity, is to agonise over the prioritising of detailed subject topics to be included in a given learning period. It is timely now for many universities' disciplines to step back from the frustration of trying to fit too much information into too little time, and to concentrate once more on the liberal education principles, suitably updated and re-interpreted for relevance.

Liberal education provides the training, skills and character to allow a holistic and wise survival and contribution to society. As socjety changes, so must education change appropriately. In the knowledge society, with its rapidly changing paradigm, the formal education to be acquired must retain a universal, holistic approach, while also preparing the student for further, life-long learning.

\section{Knowledge Available to All}

Before the recent technological ages, the accumulated knowledge of mankind's history was available only to the few who could attend at centres of learning and receive it verbally or through sparse scrolls, parchments and low volume print publications. Technology has enabled mass access to this pre-existing knowledge and to massive amounts of new information for processing into new knowledge. In the knowledge society, existing knowledge and the raw material for new knowledge are readily available to many and, conceivably, the legitimate aspiration of all. 'In the knowledge society, for the first time in history, access to leadership is open to all.,

\section{Enterprise Open to All; Increased Competition}

Enterprise is also open to all, because recognition of opportunity, and location of, and access to, resources to be mobilised are more readily available. Inevitably, there is then more competition, both for the opportunity-satisfaction role and for the resources needed to realise that. Drucker confirms this:

In fact, developed societies have already become infinitely more competitive for the individual than were the societies of the early twentieth century, let alone earlier centuries, those of the nincteenth or eighteenth centuries. Then most people had no opportunity to rise out of the class into which they were bom, with most individuals following their fathers in their work and in their station in life. ${ }^{4}$

\section{Entrepreneurship Education is Relevant}

The development of opportunities and requirements for change at an increasing rate in the knowledge society indicate a necessity for relevant education in order to survive in this environment. Entrepreneurship is the life-skill for a changing environment and entrepreneurship education is the preparatory education for flourishing in and contributing to the knowledge society. The European Commission agrees, as stated in its Action Plan dated Febnuary 2004:

Entrepreneurship ... is also a vehicle for personal development and can harness social cohesion ... A more entrepreneurial mindset is needed.

Entrepreneurship education in universities should be available for students and researchers from all fields... 


\section{Multiple Knowledges-Multiple Specialisms}

In the knowledge society, the rapid growth in knowledge inevitably has led to a multiplicity of specialisms. Drucker has coined the term knowledges to describe this development.

I have been speaking of knowledge. But the proper term is knowledges. ... The knowledge of the German allgemeine Bildung or of the Anglo-American liberal arts had little to do with one's life work. It focused on the person and the person's development, rather than on any application. Both nineteenthcentury allgemeine Bildung and liberal arts prided themselves on having no utility whatsoever. In the knowledge society, knowledge basically exists only in application. Knowledge in application is, by definition, highly specialized

Historically, workers were generalists. They did whatever had to be done on the farm, in the household and in the craftsman's shop....

Knowledge in application is effective only when it is specialized. Indeed, it is more effective the more highly specialized it is.

These concepts are interesting and provocative. The term knowledges is useful to describe the reality, but also emphasises the requirement for an approach to education and learning that will serve to integrate the otherwise disparate areas of knowledge. It seems an exaggeration to say that knowledge only exists in application, although this may be true for many new knowledge areas. It may be more accurate to say that there is a large amount of new knowledge that focuses on application, rather than on the person.

\section{Everything Has a Context}

There is an essential role for extreme specialisation, but it must be remembered that applications are rarely isolated. It is essential, for complete understanding, that all specialist studies should be contextualised, and new disciplines and knowledge sets have developed that enable society to manage at a super-ordinate level the various specialist knowledge areas. Examples are entrepreneurship, project management, and situational complexity theory, and these are an essential part of a modem university education.

\section{Multiple Specialisms Demand Integrated Understanding and Teamwork}

In medical education, as an example of complexity, there is growing interest in training physicians under complex multi-factorial conditions referred to as VUCAD (conditions of volatility, uncertainty, complexity, ambiguity and delayed feedback). This is an example of integrative learning, and it is reported: 'Medical errors can be reduced or avoided by training in both factual knowledge and in optimal information processing?. ${ }^{15}$

Drucker also develops the implication of multiple specialisms in the knowledge society to include the necessity for education in knowledge assimilation and productive team work.

... the shift from knowledge to knowledges offers tremendous opportunities to the individual. It makes possible a career as a knowledge worker. But it equally presents a great many new problems and challenges. It demands for 
the first time in history that people with knowledge take responsibility for making themselves understood by people who do not have the same knowledge base. It requires that people learn and preferably early how to assimilate into their own work specialized knowledges from other areas and other disciplines.

... That the knowledge in the knowledge society has to be highly specialized to be productive implies two new requirements: 1 . knowledge workers work in teams; and 2. knowledge workers have to have access to an organization which, in most cases, means that knowledge workers have to be employees of an organization.

... With knowledge work being the more effective the more specialized it is, teams become the actual work unit rather than the individual himself.

... It is only the organization that can provide the basic continuity which knowledge workers need to be effective. It is only the organization that can convert the specialized knowledge of the knowledge worker into performance.

... In the knowledge society, it is not the individual who performs. ... It is the organization that performs. The individual physician may have a great deal of knowledge. But the physician is impotent without the knowledge provided by a host of other scientific disciplines, i.e., physies, chemistry, geneties, etc. The physician cannot function without the test results produced by a host of diagnosticians that run the imaging machines whether X-ray or ultrasound, making and interpreting blood tests, administering brain scans, etc. The hospital is the lifeline to the physician. ${ }^{4}$

Here we see that the knowledge society paradigm is defined also by multidisciplinarity, knowledge integration, teamwork and, of necessity, facilitative management. It is essential for survival and performance in this society to have knowledge and understanding about how multi-disciplinary teams and organisations hehave and perform. These are not trivial issues, and they deal with human behaviour as much as the knowledge disciplines themselves.

\section{Integrative Learning is a Part of Liberal Education}

Integrative Leaming, therefore, must be part of all university curricula, at least at undergraduate level. According to the Association of American Colleges and Universities and The Carnegie Foundation for the Advancement of Learning:

Fostering students' ability to integrate learning ... is one of the most important goals and challenges of higher education. Integrative Learning comes in many varieties: connecting skills and knowledge from multiple sources and experiences; applying theory to practice in various settings; utilising diverse and even contradictory points of view; and, understanding issues and positions contextually. ${ }^{10}$

Their explanation of the objective and outcomes of integrarive learning shows the relevance to a university's role in the $2 l^{\text {st }}$ century.

Learning that helps develop integrative capacities is important because it builds habits of mind that prepare students to make informed judgments in the conduct of personal, professional, and civic life; such learning is, we believe, at the very heart of liberal education. ${ }^{10}$ 
All Knowledge Workers may be (Knowledge Integrating) Managers

Further, most knowledge workers are faced with the requirement to perform and manage in these multi-disciplinary situations. It is not just owmers or entrepreneurs who must manage. Drucker says:

Only late in the nineteenth century did the factory rather than the owner become the employer. And only in the twentieth century did the corporation, rather than the factory, then become the employer. Only in this $\left[20^{\text {th }}\right]$ century has the master been replaced by a boss, who, himself, ninety-nine times out of a hundred, is an employee and has a boss himself. ${ }^{4}$

An essential corollary about these organisations in which knowledge workers combine to perform is that the knowledge has a democratising effect. Each knowledge worker contributes with knowledge that is obtained independently of others.

Because its work is based on knowledge, the knowledge organization is altogether not one of superiors and subordinates. ${ }^{\ddagger}$

Knowledge workers work independently and interrelate with others spontaneously as required, not under direct instruction or formal procedure. In one sense, every knowledge worker is a manager, and the manager's job has changed to coordinating the performance and integrating the outputs of separate knowledge areas. According to Drucker the nole of the manager now is ..

... to bring people, each of them possessing a different knowledge, together for joint performance. All [managers] have to make human strengths productive in performance and human weaknesses irrelevant... The essence of management is to make knowledges productive. Management, in other words, is a social function. And, in its practice, management is truly a liberal art. $^{4}$

\section{Hierarchical Liberalisation}

While criticising excessive specialisation in university educational programmes, it is not satisfactory to promote the other extreme. In resolving the specialisationliberalisation dilemma in education, an approach that might be called hierarchical liberalisation of educational programmes should be adopted. Each course programme should be taught according to a principle of maximum integration, i.e. at the highest level of principles, as opposed to details, and at the highest level of integration with a broad range of other subject areas that is consistent with maintaining a capability for life-long learning and self-learning in the reference course area. Subject matter details are used for demonstration and elucidation of principle rather than for their own sake. More and more in a knowledge-based society, facts and procedures are commodities and easily accessed, but appreciation and understanding of principles of behaviour are valuable assets for use in varied circumstances. Each subject should be liberalised to the maximum extent as above, so that a hierarchy is created where liberalism is promoted, but allowing trade-off between breadth and depth for various purposes. 


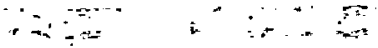

Is Liberal Engineering, for example, Reasonable?

As an example, there is growing interest now in re-introducing a more liberal content to Engineering education, although this is still at an early stage. ${ }^{16}$ Note the term reintroducing is appropriate, considering that the separation of Engineering from the Liberal Arts subjects has occurred only through the last two centuries. Leonardo da Vinci and Michelangelo, before this, were well known practitioners of both Liberal Arts and Engineering, which multi-disciplinarity was common at that time and with good effect.

In one approach to liberalising Engineering education, the subjects of Liberal Arts are simply taught alongside the pure engineering subjects. While undoubtedly better for the engineering student than no exposure to these broader ranges of subjects, such an arrangement is sometimes akin to tokenism and often perpetuates a separation of the two subject areas, except where exceptional students may be able intrinsically to appreciate an integration of the two.

True liberal Engineering education will develop understanding of the principles of good engineering practice rather than concentrating excessively on mere facts. It will seek out and amplify the connectedness between such principles and their application in other life circumstances as well as vice versa, applying principles from other disciplines to engineering circumstances. Control Systems Engineering is an example that is sometimes applied to other non-engineering application areas and in so doing brings understanding benefits to all sides. But, this process can be carried on throughout all topics. For example, most engineering students are taught about measurement systems and mensuration, including the ideas and importance of accuracy, resolution and the influence of measuring devices. There is opportunity here to expand on the relationship to analogous or closely similar principles important in many other subject areas from theoretical physics (e.g. the Heisenberg Uncertainty Principle) to Criminal Law (scene-of-crime witness statements' accuracy) and many other areas. True Liberal Engineering education will carry on this liberalisation as a systematic and widespread process rather than occasionally or ad-hoc.

\section{Knowledge Its Own End a Realistic Aspiration}

There is another real benefit available to an individual in the knowledge socjety, relating back to Newman's Idea of a University aspirations. The knowledge economy that is part of the knowledge society needs continuing knowledge advancement to support economic advancement. Simultaneously, the knowledge worker as an individual may seek more knowledge for greater fulfilment, as acknowledged earlier under knowledge its own end. There is a happy overlap between these two requirements and the satisfaction of both needs is a realistic and legitimate aspiration in a knowledge economy.

\section{Conclusion}

What Should be the Role of a University in the Knowledge Society?

It seems practical as well as elegantly traditional, while nevertheless maintaining contemporary relevance, to maintain the notion of a university as a place of universal, liberal learning. Crucially, the understanding of universality and liberality must be updated to accommodate the new paradigm of the knowledge society. 
The modern liberal education has the same aim as of old but has changed in scope. As well as the traditional Humanities education the modern liberal education must treat of the multiple extra knowledge dimensions and the integration of such varied knowledge.

The aim of the liberal education remains as stated by Newman, namely to cultivate ...

that training of the intellect, which is best for the individual himself [and] best enables him to discharge his duties to society.'

More recently the Association of American Colleges and Universities has stated:

A touly liberal education is one that prepares us to live responsible, productive, and creative lives in a dramatically changing world. It is an education that fosters a well-grounded intellectual resilience, a disposition toward lifelong learning, and an acceptance of responsibility for the ethical consequences of our ideas and actions.

\section{University in a Community of Knowledge Institutions, with Teaching the Primary Role}

The university must also realise that, in the knowledge society, it no longer commands the role of a unique, exclusive place of knowledge or knowledge advancement. It is one type of institution among many institutions. Its business is knowledge extension, advancement and diffusion, i.e. teaching, research/practice and publication, in that order! The other knowledge institutions are variously state-funded, privately-funded, non-profit and for-profit institutions, some of which have missions that are directly educational and some that are not. The university no longer can behave as an ivory tower with presumed exclusive access to knowledge, but it can still have a particular role as a teacher of universal knowledge in provision of a liberal education.

\section{Practice Informed Teaching}

Universities have often behaved as separate and distinct from the rest of society, with sometimes-doubtful relevance to that society. In order to continue being able properly to teach such knowledge, the university must engage substantially more than heretofore with the other various knowledge institutions, as university based research is a diminishing fraction of total knowledge advancement. The engagement must be continuous, intimate, multi-level and real rather than token. The rubric Research Informed Teaching, as hitherto understood, then requires amendment and restatement as Practice Informed Teaching, because university based research alone is no longer adequate for informing a teacher of the latest knowledge advancements.

\section{Broader Staff Experience}

The university must adapt to encourage fluidity of experience of its teaching staff inside the university, between faculties, as well as outside, among separate institutions, so that they have a more general exposure to the different areas of knowledge and their application. 


\section{Integrative Leaming Education}

Compared to other knowledge institution types, there is a unique role for the university and that role is knowledge integration. In seeking to understand the connectedness and broader truths of the knowledge advancements from different sources, the university can better complement other institutions with this unique role, and in so doing create a better environment for supporting liberal teaching.

\section{Attendance is Mandatory for Experiential Learning}

Integrative Learning is an experiential process and the practice of knowledge integration is a mental process that, in turn, must be practised. If the integrative learning is to be experienced, this obviously requires high attendance of students at course sessions. This is a challenge for programme organisation and management. Universities also must rise to the challenge of assessment of knowledge integration capabilities, which is not an easy task.

\section{Archivist}

This traditional role of a university remains central, unique and valuable. The archiving of old and otherwise infrequently used knowledge is very important for society.

\section{Sammary}

The modern university should provide a liberal education as properly understood in a knowledge society. This requires a university to be inclusive, a peer in a global knowledge democratisation, rather than ivory tower elitist.

Knowledge is multi-disciplinary and the university has a special role as connector of the various disciplines, through knowledge integration.

The university can fulfil its liberal education primary role as teacher of universal knowledge only with teacher expertise maintained by regular exposure of teachers to the variety of practice-modes of knowledge application, advancement and integration. Practice Informed Teaching is a more appropriate ideal description than Research Informed Teaching.

1. Newman, J.H., The Idea of a University. (Dublin, 1852), Preface.

2. Ibid., Discourse 5 .

3. Newman, J. H., quoted in Pelikan, note 9, p. 82.

4. Drucker, Peter F., Knowledge Work and Knowledge Society-The Social Transformations of this Century. Edwin L. Godkin Lecture, Harvard University, John F. Kennedy School of Government, 1994.

5. Creech, Bill, The Five Pillars of TQM: How to Make Total Quality Management Work for You. (New Youk: Trunan Talley Books, E. P. Dutton, 1994).

6. Building Ireland's Knowledge Economy-The Irish Action Plan for Promoting Investment in R\&D to 2010. Inter-Departmental Steering Group Report to the Inter-Departmental Committee on Seience, Technology and Innovation, July 2004.

7. European Union, The Lisbon Agenda: in March 2000, the EU Heads of States and Governments agreed to make the EU 'the most competitive and dynamic knowledge-driven economy by 2010'.

8. European Union, Acrion Plan: The European Agenda for Entreprenewrship. Communication from the Commission of the European Communities to the Couneil, The European Parliament, The European Economic and Social Committee and the Committee of the Regions, COM(2004) 70 final, (Brussels, 11.2.20104). 
9. Pelikan, Jaroslav, The Idea of the Universin-a Reexamination. (New Haven: Yale University Press, 1992).

10. Huber, Mary T., and Hutchings, Pat, Integrative Learning-Mapping the Terrain. Association of American Colleges and Universities and The Camegie Foundation for the Advancement of Learning, (Washington DC: $A A C U, 2004)$.

11. von Hamack, Adolf, Munich: October 1929 (quoted in Pelikan, note 9, p. 84).

12. Jones, G. R., and George, L.M., Essentials of Consemporary Management. (New York: MeGrawHill, 2004).

13. Schumpeter, Joseph, Theorie der Wirfschafflichen Entwicklung. (Munich, 1912).

14. Association of American Colleges and Universities: Stasement on Liberal Learning, htup://www, aacu-edu,org/About/statements/liberal leaming,efm, 2004.

15. Satish, U., and Streufert, S., 'Value of a Cognitive Simulation in Medicine: Towards Optimizing Decision Making Performance of Healthcare Personnel', (BMJ, Quality and Safety in Healthcare, 11, pp. 163-167, 2002); online: http://ahc,bmijoumals.conicgi/content/full/11/2/163

16. Uddin, Mahbub, Liberation of International Engineering Education with the Paradigm of Liberal Engineering. (ICEE '99); online:

hitp://www.ineer.0ro/Events//CEE 1999/Proceedings/papers/402/402.htm

17. Hogan, P., '[OECD] Report Threatens Third-level Values', (Dublin: Irish Times, $11^{\text {t }}$ March, 2005), Supplement: 'Working in Education', p. 12.

18. Dees, Gregory J., 'The Meaning of Social Entrepreneurship', Stanford Graduate Business School Researeb Paper, May 2001.

19. Drucker, Peter, Innovotion and Enrrepreneurship. (Harper Business, May 1993).

20. Adizes, Ichak, Corporate Lifecycles-How and Why Organisations Grow and Die and What to Do About It. (New Jersey, Prentice Hall, 1988).

21. quoted by Dees, note 18 . 